\title{
SELF-ASSEMBLED PARALLEL MESOSCOPIC Pb WIRES ON VICINAL Si(111)
}

\author{
M. JAEOCHOWSKI \\ Institute of Physics, Maria Curie-Skłodowska University \\ Pl. M. Curie-Skłodowskiej 1, 20-031 Lublin, Poland
}

\begin{abstract}
The work presents a novel method of production of mesoscopic metallic wires on semiconducting surfaces. Making use the self-assembly phenomenon, arrays of extremely long and perfectly parallel mesoscopic $\mathrm{Pb}$-wires on vicinal $\mathrm{Si}(111)$ substrates are formed and studied in UHV conditions. Before deposition of $\mathrm{Pb}$ a uniform distribution of monoatomic steps and terraces was induced by formation of Au chains running along step edges. The wires growing on the substrates held at temperatures close to the room temperature reach up to $8 \mu \mathrm{m}$ length. A reflection high electron energy diffraction experiment shows that the wires laying on $\mathrm{Si}(533)$ along the step edges have triangular cross-section determined by (111) and (100) facets of $\mathrm{Pb}$. Scanning tunneling microscopy images collected at low temperatures have enabled us to determine details of the wires shape and morphology of the substrate. The width of the wires was approximately equal to $60 \mathrm{~nm}$ whereas their height was about $10 \mathrm{~nm}$. The observed strong growth anisotropy is attributed to step edge barriers and high $\mathrm{Pb}$ mobility on the smooth $\mathrm{Si}(111)$ narrow terraces that form vicinal surfaces and the anisotropic strain due to large misfit between $\mathrm{Pb}$ and $\mathrm{Si}$ lattices.
\end{abstract}

PACS numbers: $68.35 . \mathrm{Bs}, 68.55 . \mathrm{Jk}, 68.65 .+\mathrm{g}, 81.15 . \mathrm{Ef}, 61.16 . \mathrm{Ch}$

\section{Introduction}

A wide variety of physical phenomena of mesoscopic structures relies on details of their shape. Recently the growth of $\mathrm{Pb}$ on $\mathrm{Si}(111)$ surfaces has been studied thoroughly $[1,2]$ as a model system consisting of metal on semiconducting surface. At low temperatures for the samples with a thickness of a few $\mathrm{Pb}(111)$ monoatomic layers pronounced quantum size effects (QSE) in two-dimensional ultrathin films were observed and discussed [2,3]. It is supposed that these effects have an impact on morphology of growing $\mathrm{Pb}$ which manifests as preferences in the height of flat islands on $\mathrm{Si}(111)$ surfaces.

Previously we have observed the relaxation of $\mathrm{Pb}$ thin films during growth on flat $\mathrm{Si}(111)$ substrates. Onto cooled substrates we found an amorphous-like 
initial grow th mode. The phase transition into crystalline state occurred after some critical thickness and was associated with a large crystal lattice missfit between $\mathrm{Pb}$ and $\mathrm{Si}$ equal to $8 \%$. At $70 \mathrm{~K}$ it was 4 monoatomic layers (ML) of $\mathrm{Pb}(111)$, at $18 \mathrm{~K}-7 \mathrm{ML}$. After the transition the resulting crystalline phase was flat and well oriented. At higher temperatures this critical thickness decreases and simultaneously sparse three-dimensional $\mathrm{Pb}$ islands were formed. The orientation of islands was $\mathrm{Pb}(111) \| \mathrm{Si}(111)$ and $\mathrm{Pb}[1 \overline{1} 0] \| \mathrm{Si}[11 \overline{2}]$. Due to threefold symmetry of $\mathrm{Si}(111)$ surface the islands grew in three equivalent orientations. It is reasonable to suppose that the reduction of the substrate symmetry can force the $\mathrm{Pb}$ islands to orient in one desired direction. Such elongated islands could serve as a convenient system for studying the quasi-one-dimensional QSE in metallic nanowires.

It has been shown that self-organization of islands on crystalline substrate are closely related to the relaxation of misfit stress between two different materials. Tersoff and Tromp [4] have shown that a very large length (width ratios greater than 50:1) can be obtained also when the misfit is not anisotropic ( $\mathrm{Ag}$ on $\mathrm{Si}(100)$ ). We expect that both factors, misfit and substrate anisotropy, can force the growing crystal to form a matrix of parallel mesoscopic wires instead of a thin film.

It is well known that vicinal $\mathrm{Si}(111)$ surfaces are usually highly disordered. Although at high temperatures the steps are distributed uniformly, upon cooling step bunching occurs [5]. At temperatures below the $\mathrm{Si}(1 \times 1) \leftrightarrow(7 \times 7)$ surface reconstruction transition the surface consists of reconstructed $\operatorname{Si}(111)-(7 \times 7)$ terraces and step bunches $[6,7]$. Below $870^{\circ} \mathrm{C}$ the flat vicinal surface breaks up into a hill-and-valley structure [8]. It is clear that these substrates are not well suited for the growth of ordered wires. Therefore, in order to obtain a uniform distribution of steps and terraces an additional technological processing is necessary.

It was established previously that for $\mathrm{Si}(755)$ a perfect and uniform distribution of monoatomic steps can be obtained for certain coverage of $\mathrm{Au}$ and following the annealing of the sample [9]. An optimal coverage corresponded to the amount of $\mathrm{Au}$ required to form a single chain of $\mathrm{Au}$ atoms on each $\mathrm{Si}(111)$ terrace. Any deviation from that coverage toward smaller or larger coverages caused the formation of other than $\mathrm{Si}(755)$ facets. Apparently one-dimensional single chains of Au stabilize the surface and prevent the formation of step bunches.

In this work we report on investigation of $\mathrm{Si}(533)$ surface covered with a submonolayer amount of $\mathrm{Au}$. Using reflection high electron energy diffraction (RHEED) and scanning tunneling microscopy (STM) techniques an optimal Au coverage that leads to developing a well-ordered and uniform $\mathrm{Si}(533)$ facet is established. High asymmetry in the morphology of this surface on the atomic scale assures that highly asymmetrical, one-dimensional diffusion of $\mathrm{Pb}$-adatoms can be achieved. One-dimensional diffusion with conjunction with asymmetrical lattice constant misfit leads to the formation of extremely long, parallel mesoscopic $\mathrm{Pb}$ wires.

\section{Experimental}

The substrates were $\operatorname{Si}(533)$ crystals with a vicinal angle equal $14.42^{\circ}$ to (111) plane. The orientation of the (533) plane was determined with an accuracy 
within \pm 0.03 deg. The samples had the dimensions of $13 \times 4 \times 0.6 \mathrm{~mm}^{3}, 500 \Omega \mathrm{cm}$ specific resistivity at room temperature and were mounted with cooled Mo clamps on the ultra high vacuum low energy electron microscope (UHV LEEM) cartridge. Flashing for a few seconds to about $1500 \mathrm{~K}$ removed the oxide layer and produced a well-ordered $(7 \times 7)$ superstructure on which other diffraction reflexes originating from the step bunching were superimposed. Resistive dc heating was used.

A uniform distribution of monoatomic steps was induced using the method developed previously [9]. A submonolayer amount of Au was deposited onto the bare substrate at room temperature. Subsequently the sample was annealed for $0.5 \mathrm{~min}$ at about $900 \mathrm{~K}$ and the temperature was gradually lowered over the next $1.5 \mathrm{~min}$. The optimal amount of the $\mathrm{Au}$ deposit was determined to be $0.28 \pm 0.02 \mathrm{ML}$ ( $1 \mathrm{ML}$ corresponds to the density of $\mathrm{Si}$ atoms in $1 / 2$ bilayer of $\mathrm{Si}(111)$ ). At this coverage only (533) RHEED reflexes were visible. These surfaces were stable and sustained multiple cycles of annealing up to $900 \mathrm{~K}$.

The RHEED system consisted of an electron gun with magnetic focusing lens and deflection coils, a Faraday cup for collection of the specularly reflected electrons and a CCD camera for recording the RHEED pattern displayed on a fluorescent screen. This system could operate anywhere within the electron energy from 10 up to $25 \mathrm{keV}$. The instrumental limitation (the transfer length) of the RHEED electronooptics and fluorescent screen used, estimated using a flat $\mathrm{Si}(111)$ surface with a $(7 \times 7)$ superstructure was $20 \mathrm{~nm}$ normal to the incident direction and exceeded $0.5 \mu \mathrm{m}$ in the plane of the electron beam incidence.

A precise quartz-crystal monitor with frequency-to-voltage converter allowed one to control the deposition of Au with a great accuracy. The monitor was calibrated with the RHHED intensity oscillation technique. During deposition of $\mathrm{Au}$ on cooled $\mathrm{Si}(111)$ several periods of specularly reflected electron intensity oscillations corresponding to $1 \mathrm{ML}$ of $\mathrm{Au}$ could be recorded. Using this method in this work the coverage of vicinal $\mathrm{Si}$ with $\mathrm{Au}$ was controlled with an accuracy better than 1/50 ML of (111) fcc Au.

Real-time surface imaging was performed using a compact electrostatic LEEM instrument [10] which after some modifications routinely achieved spatial resolution better than $20 \mathrm{~nm}$. Pb was evaporated from a Ta crucible placed at a glancing angle of $30^{\circ}$. The deposition rate was $1.3 \mathrm{ML} \mathrm{Pb}(111)$ per minute, and a variety of substrate temperatures was used. During deposition LEEM images were acquired every $5 \mathrm{~s}$.

The low-temperature STM (VT STM of OMICRON) was operated in a constant current mode. Si(533) substrates after their preparation in the main chamber of UHV system were transferred to STM and cooled-down with a LHe cryostat that enables one to reach $50 \mathrm{~K}$ at the sample. $\mathrm{Pb}$ was evaporated during operation of STM from Mo-crucible placed at the angle $60^{\circ}$ to the sample normal. A tip was made from a polycrystalline tungsten wire. by electrochemically etching in $2 \mathrm{~N}$ $\mathrm{KOH}$. Only tips that gave single and reproducible images of $\mathrm{Pb}$ structures were chosen for measurements. 


\section{Results and discussion}

\subsection{Au-induced ordering on Si(533) surface}

The RHEED technique allows one to precisely examine reconstructions on $\mathrm{Si}(533)$ induced by $\mathrm{Au}$ on the long-range scale. We have studied electron diffraction in both parallel and perpendicular to the step edges directions. In this work only the results for electron beam parallel to the step edges are presented.

Diffraction from a bare $\mathrm{Si}(533)$ did not show the existence of a regular stepped structure on the surface. In Fig. 1a several spots originating from the disordered Si(533) surface form a smeared 0th Laue zone (LZ). After deposition of a small amount of $\mathrm{Au}$ we observed development of regularly spaced streaks. These streaks are identified as originating from regularly spaced terraces with the width equal to $1.23 \pm 0.015 \mathrm{~nm}$, that is close to $1.219 \mathrm{~nm}$ expected for unreconstructed $\mathrm{Si}(533)$ surface [11].
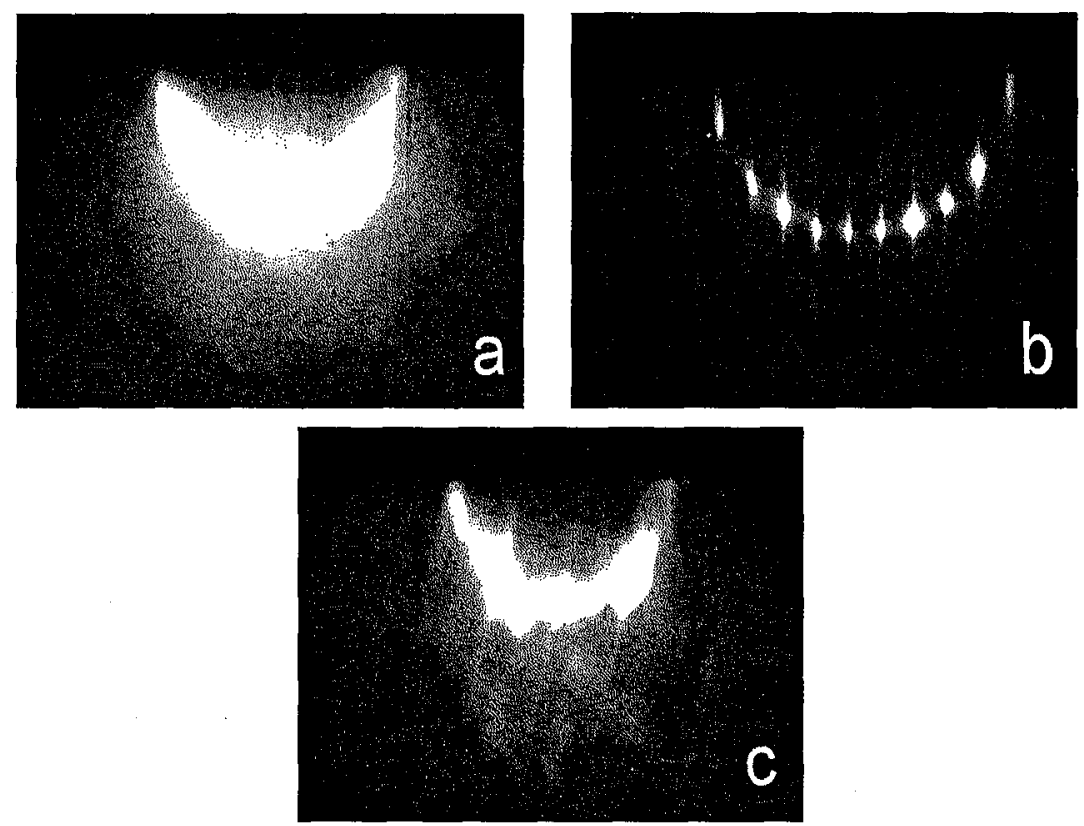

Fig. 1. 0th Laue zone of RHHED pattern of $\mathrm{Si}(533)$ surface at $250 \mathrm{~K}$. Electron energy is $20 \mathrm{keV}$. The incidence azimuth is parallel to the step edge ([011]) direction. The macroscopic plane of the crystal is parallel to the horizontal edge of the image. (a) Clean Si. (b) Si covered with 0.28. ML of Au. (c) Si covered with $0.65 \mathrm{ML}$ of Au. The gray scale of the image is arranged logarithmically.

The best developed set of regularly spaced streaks perpendicular to the macroscopic Si(533) surface was achieved for the Au coverage equal to $0.28 \mathrm{ML}$, as it is shown in Fig. 1b. The unit cell size in the plane (111) for unreconstructed (533) surface is equal to $3 \frac{2}{3} \times a_{[\overline{112}]}=1.22 \mathrm{~nm}$. The unreconstructed surface unit 
cell observed in our experiment has the size $3 \frac{2}{3} a_{[\overline{11} 2]} \times 1 a_{[1 \overline{1} 0]}$. If we suppose that only a single $\mathrm{Au}$ atom occupies one unit cell then the corresponding coverage is $1 /\left(3 \frac{2}{3}\right)=0.273$. This density of Au atoms projected on Si(533) surface corresponds to the coverage equal to $0.282 \mathrm{ML}$, that is very close to the optimal value found for the best ordered surface.

Surfaces with a larger amount of Au split into regions with wide (111) terraces and high index facets. Figure 1c shows a RHEED diffraction pattern of 0 th LZ for the sample with $0.65 \mathrm{ML}$ of Au. Similarly as in (a) the pattern shows structures from the disordered surface. The complete diffraction pattern showed that at coverages close to $0.60 \mathrm{ML}$ of $\mathrm{Au}$ strong diffraction features originating from $(\sqrt{3} \times \sqrt{3}) R 30^{\circ} \mathrm{Au}$ reconstruction on $\mathrm{Si}(111)$ terraces and from (311) facets were superimposed. Interestingly, the similar phenomenon was observed for $\mathrm{Si}(755)$ facet where an optimal Au-coverage was established as equal to 0.20 ML [9]. Apparently the formation of single-atom chains running along the steps stabilize the surface.

\section{2. $\mathrm{Pb}$ wires}

Morphology of $\mathrm{Si}(533)$ has a decisive impact on the growth of $\mathrm{Pb}$ islands. Figure 2 shows LEEM images taken after deposition of $6.6 \mathrm{ML}$ of $\mathrm{Pb}$ on $\mathrm{Si}(533)$ at $280 \mathrm{~K}$. Visible in (a) and (b) islands appear abruptly after deposition of about
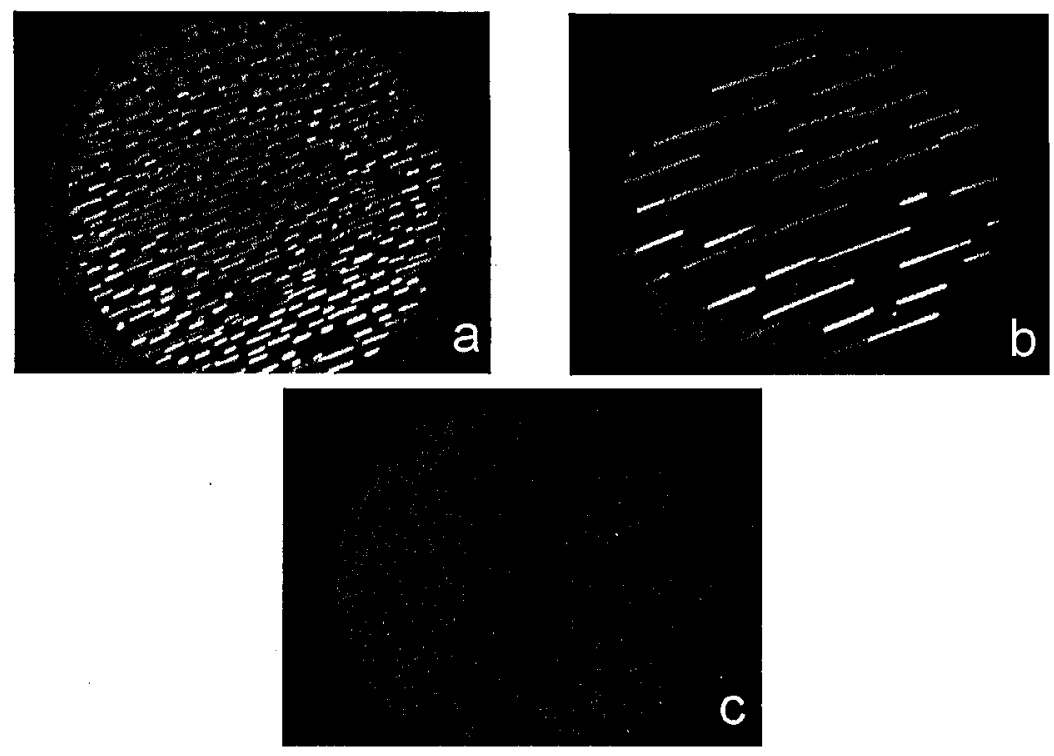

Fig. 2. LEEM images recorded after deposition of $6.6 \mathrm{ML}$ of $\mathrm{Pb}$ at $280 \mathrm{~K}$ on $\mathrm{Si}(533)$ with various amounts of $\mathrm{Au}$. The substrate in (a) was clean Si. In (b) and (c) the amount of $A u$ was 0.28 and $0.63 \mathrm{ML}$. In (c) the islands are not resolved by LEEM. Electron energy is $7.4 \mathrm{eV}$. The wires are oriented along the step edges of $\mathrm{Si}(533)$. The diameter of the image corresponds to $8 \mu \mathrm{m}$ of the sample. 
$1 \mathrm{ML}$ of $\mathrm{Pb}$. Islands in (c) are unresolved by LEEM. The substrate in (a) is bare $\mathrm{Si}(533)$. The substrates in (b) and (c) are covered with 0.28 and 0.63 ML of Au. During further deposition, up to $12 \mathrm{ML}$ of $\mathrm{Pb}$, no new islands were observed to nucleate. Most notably, the islands grew only in the step direction. At least up to $12 \mathrm{ML}$ of $\mathrm{Pb}$ no variation of the width of separated wires could be detected within the limits set by the resolution of the LEEM microscope. The density of islands established during sudden nucleation strongly depends on the perfection of $\mathrm{Si}(533)$ substrate. The most pronounced, wire-like long islands are grown on the well-ordered $\mathrm{Si}(533)$ with $0.28 \mathrm{ML}$ of $\mathrm{Au}$.

The orientation of elongated $\mathrm{Pb}$ facets forming the wires was determined from RHEED patterns. Figure 3 shows a set of patterns recorded during the deposition of $\mathrm{Pb}$ onto $\mathrm{Si}(533) / 0.28 \mathrm{ML}$ of $\mathrm{Au}$ at $\mathrm{RT}$. The corresponding coverages (in units of $\mathrm{Pb}(111) \mathrm{ML}$ ) are 1, 3, and 20 for Fig. 3a, b, and c, respectively. In the early stage of the deposition (Fig. 3a) only suppressed $\mathrm{Si}(533)$ streaks are seen. After the deposition of more than 1.25 $\mathrm{ML}$ of $\mathrm{Pb}$ narrow streaks due to $\mathrm{Pb}$ planes (111) and (100) appear in the RHEED images. Thus Pb grew on Si(533) with the orientation of $\mathrm{Pb}(111) \| \mathrm{Si}(111)$.

In order to elucidate the origin of a sudden appearance of the islands after deposition of more than $1 \mathrm{ML}$ of $\mathrm{Pb}$ we have determined their appearance

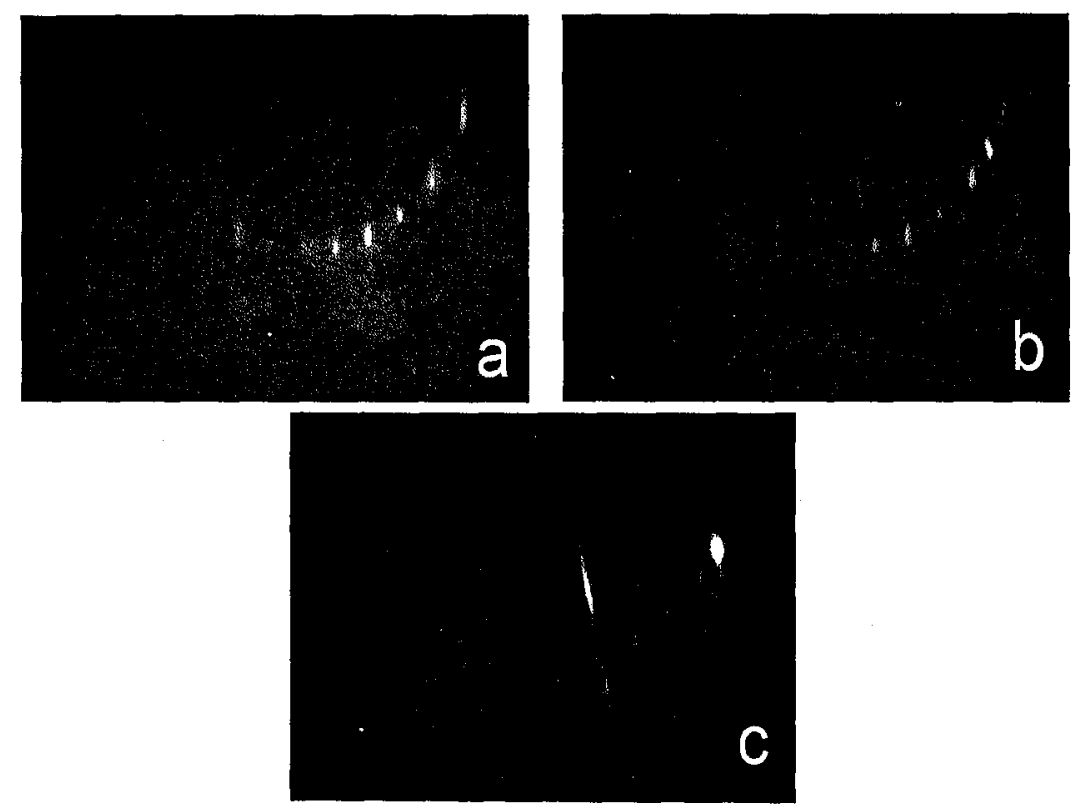

Fig. 3. Set of RHEED patterns recorded during $\mathrm{Pb}$ deposition at $\mathrm{RT}$ onto well-ordered $\mathrm{Si}(533)$ substrate with $0.28 \mathrm{ML}$ of $\mathrm{Au}$. Electron energy is $20 \mathrm{keV}$. The electron beam is directed along the step edges. Corresponding coverages are 1,3 , and $20 \mathrm{ML}$ of $\mathrm{Pb}$ in (a), (b), and (c), respectively. In (b) and (c) elongated streaks from (111) and (100) facets of $\mathrm{Pb}$ are visible. 
at different substrate temperatures. Interestingly, within the temperature range from $207 \mathrm{~K}$ to $307 \mathrm{~K}$ the appearance coverage was constant and corresponded to about $1 \mathrm{ML}$ of $\mathrm{Pb}$. After the initial islands have appeared, no additional nucleation was observed with a further deposition of $\mathrm{Pb}$. Obviously $\mathrm{Pb}$ atoms are highly mobile and the $\mathrm{Si}(533)$ surface with $1 \mathrm{ML}$ thick wetting layer is very smooth. Gómez-Rodrigues et al. [12] have investigated with STM the diffusion of single $\mathrm{Pb}$ atoms on $\mathrm{Si}(111)-(7 \times 7)$ and $\mathrm{Si}(111)-(5 \times 5)$ substrates. They found that $\mathrm{Pb}$ is highly mobile at room temperature inside the $(7 \times 7)$ or $(5 \times 5)$ half-cells but diffuses at very low rates $\left(2 \times 10^{-5}\right.$ jumps/atom/s at RT) to the neighbor half-cells. It is reasonable to assume that barriers between the terraces on vicinal surface play a similar role as the barriers between $(7 \times 7)$ or $(5 \times 5)$ half-cells in the experiment of Gómez-Rodriguez et al. [12]. The set of parallel barriers produces an asymme-
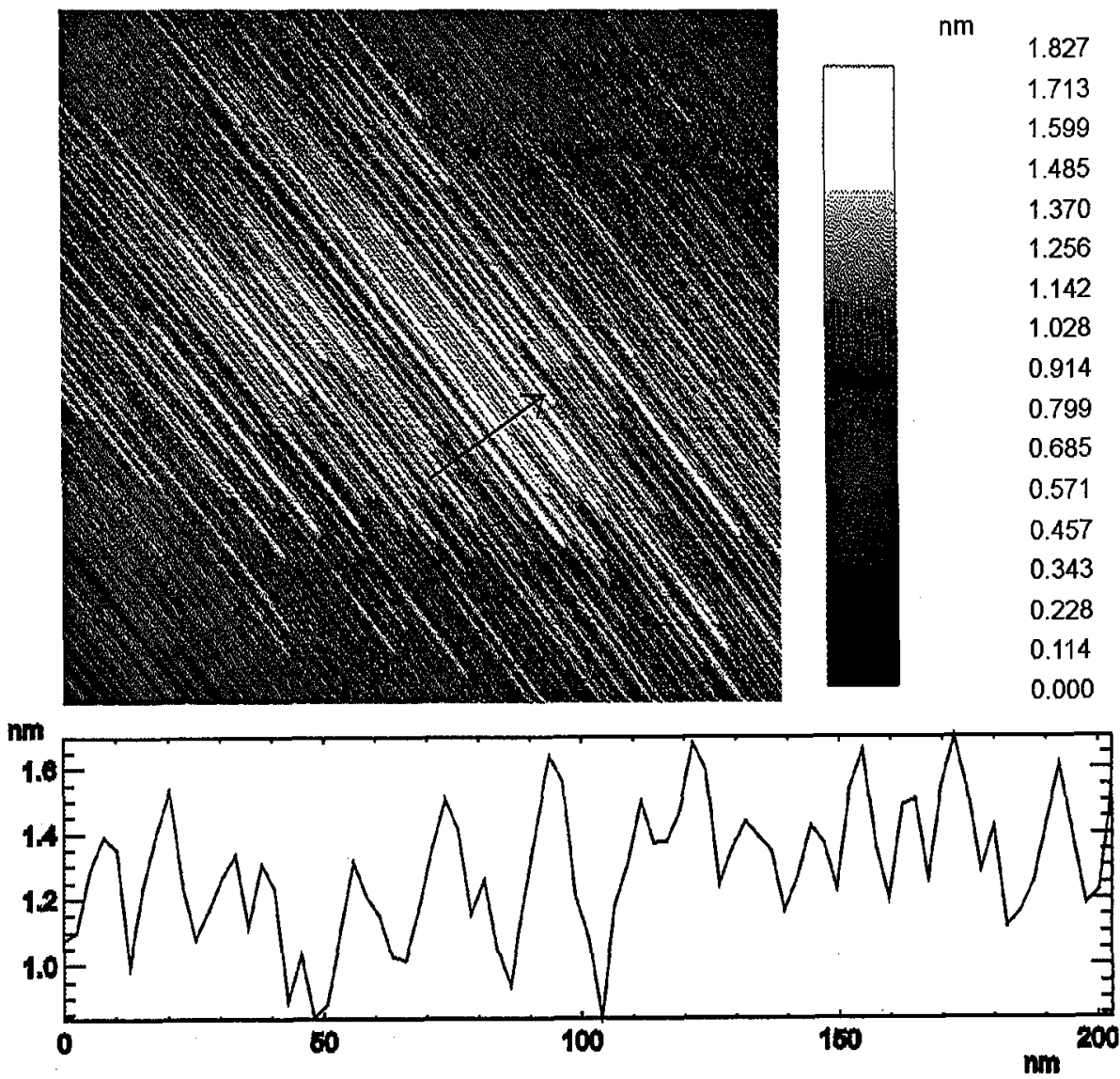

Fig. 4. STM image of clean $\operatorname{Si}(533)$ after flashing to about $1200^{\circ} \mathrm{C}$. The size of the image is $1000 \times 1000 \mathrm{~nm}$. The image was recorded at a constant current mode of $1.2 \mathrm{nA}$ and the sample bias of $2.04 \mathrm{~V}$. Step bunches and terraces of Si are running along ([011] $)$ azimuth. 
try in the mass transport on the $\mathrm{Si}(533)$ surface; much more $\mathrm{Pb}$ atoms attach to the end faces of the wires than to the elongated ridges. The atoms supplied by the continuous $\mathrm{Pb}$ vapor flux move freely along steps until they are captured by the growing crystal. Thus the growth rate of the wire depends on the unoccupied substrate area between the neighbor islands growing on the same $\operatorname{Si}(111)$ terraces.

This mechanism can operate only within a limited temperature range. At higher temperatures the barriers become transparent for $\mathrm{Pb}$ atom diffusion and the asymmetry is lost. In fact, during deposition at $326 \mathrm{~K}$ the islands grew also perpendicular to the step edges and developed trapezoidal and triangular shapes similar to that during the growth on $\mathrm{Si}(111)$ surface.

Even at temperatures as low as $188 \mathrm{~K}$, when the surface diffusion is strongly suppressed, the islands developed a wire-like form and were aligned along steps. The initial density of the wires strongly increased with decreasing temperature,

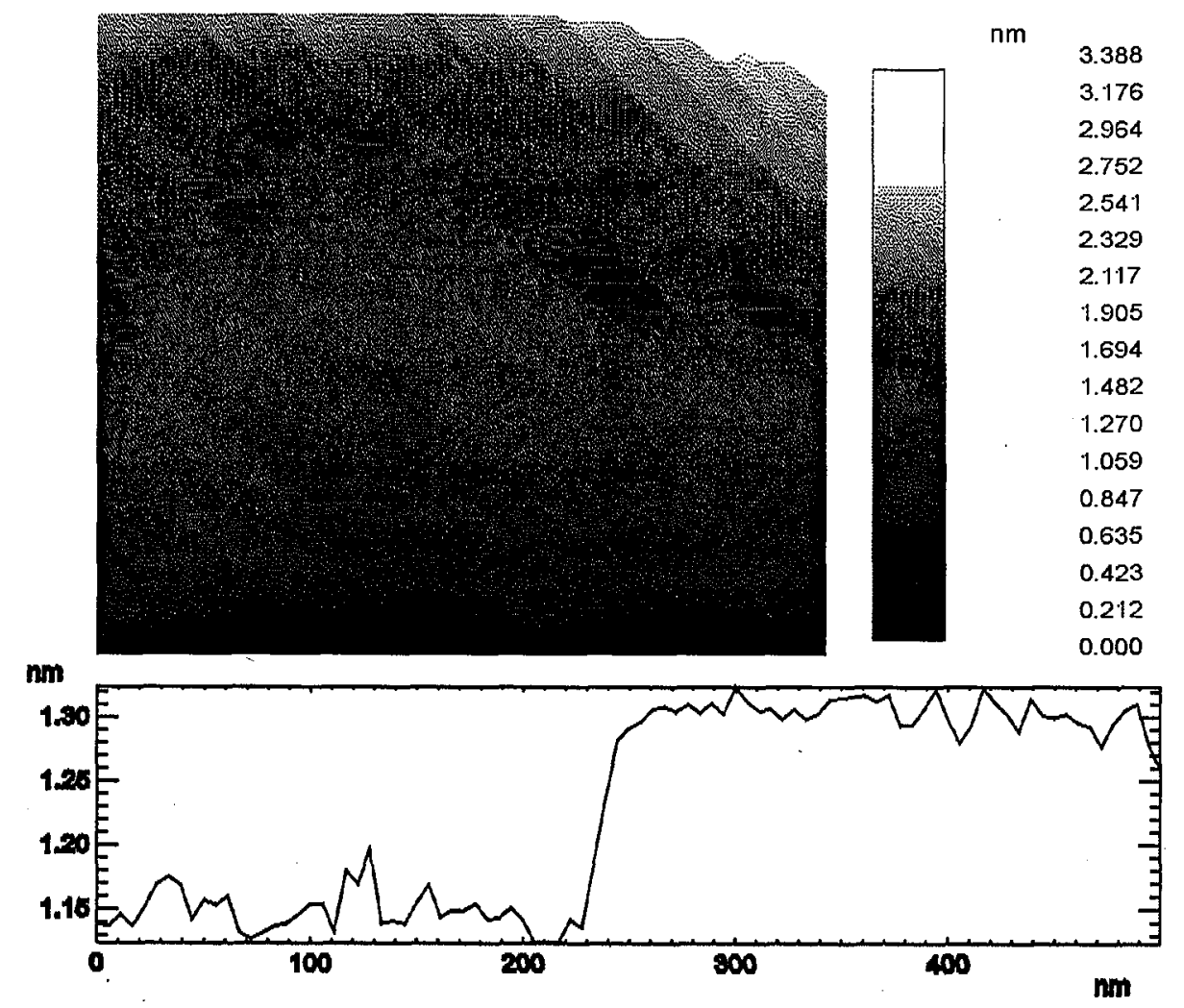

Fig. 5. STM image of clean $\mathrm{Si}(533)$ covered with $0.28 \mathrm{ML}$ of $\mathrm{Au}$. The size of the image is $2000 \times 2000 \mathrm{~nm}$. The image was recorded at a constant current mode of $0.56 \mathrm{nA}$ and sample bias of $2.15 \mathrm{~V}$. Visible large well-ordered $\mathrm{Si}(533)$ facets are separated by monoatomic steps. 
and at $173 \mathrm{~K}$ the separate islands could not be resolved by LEEM. Simultaneously the thickness of the wires decreased and finally, at very low temperatures, the substrate was uniformly covered with a thin layer of $\mathrm{Pb}$.

Figure 4 shows a STM image of the step structure of bare Si(533) surface. This surface was prepared by flashing of $\mathrm{Si}(533)$ several times for $3 \mathrm{~s}$ up to about $1200^{\circ} \mathrm{C}$. The bunches of steps and $\mathrm{Si}(111)$ terraces visible as lines are running along [011] azimuth. A pronounced change of this morphology was observed after the deposition of $0.28 \mathrm{ML} \mathrm{Au}$ and following the annealing with direct current flowing along the steps. Figure 5 shows an image of such perfectly ordered $\mathrm{Si}(533) / 0.28$ ML Au surface. A close inspection of the STM images shows that this surface consists of parallel running structures separated by deep grooves. The periodicity of this structure is about $1.2 \mathrm{~nm}$, which is close to a separation of unreconstructed steps of $\mathrm{Si}(533)$.

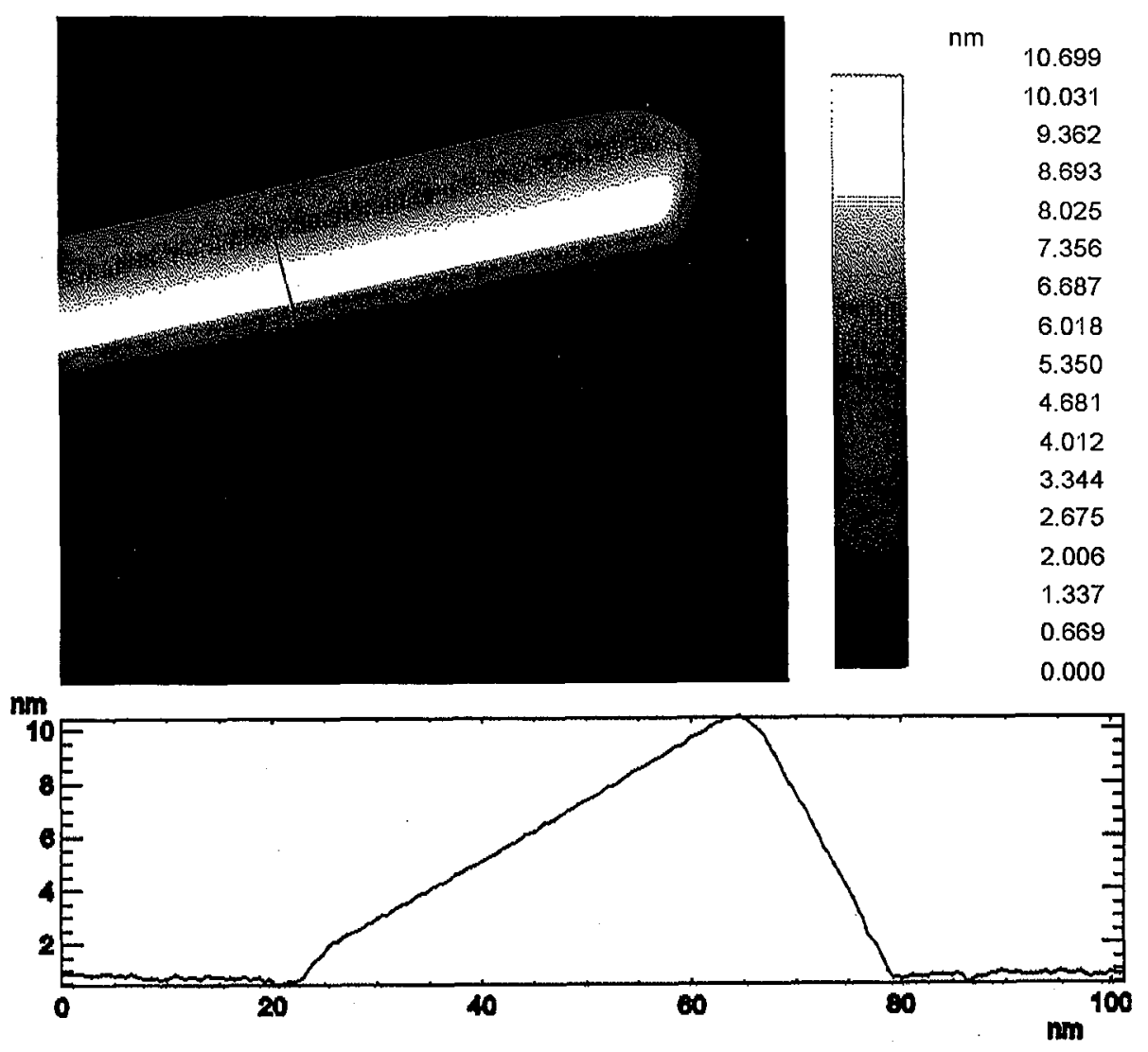

Fig. 6. STM image of a part of $\mathrm{Pb}$ nanowire. The panel at the bottom shows cross-section of the wire. The image was recorded at a constant current mode of $3.53 \mathrm{nA}$ and sample bias of $1.93 \mathrm{~V}$. 


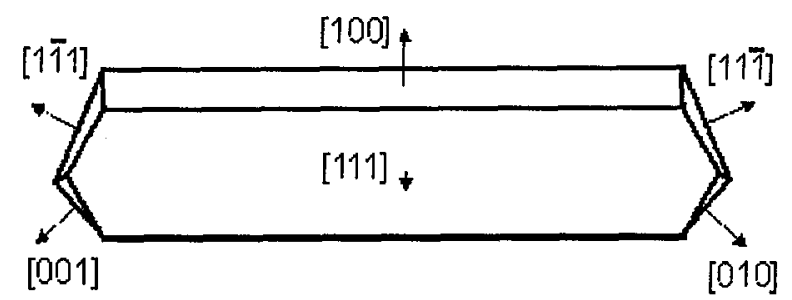

Fig. 7. Model of the mesoscopic wire derived from RHEED and STM measurements. The width of the wire is $60 \mathrm{~nm}$ and its length reaches several $\mu \mathrm{m}$.

STM allows for a detailed examination of the shape of $\mathrm{Pb}$ nanowires. STM image of a part of $\mathrm{Pb}$ nanowires is shown in Fig. 6. The inclination of the facets that form the wire could be determined from the corresponding profiles. These measurements supported by the RHEED patterns similar to that presented in Fig. 3 allow one to develop a model of the wire. Figure 7 shows schematically the shape of the nanowire. All wires obtained when the average $\mathrm{Pb}$ coverage of about $2 \mathrm{ML}$ was deposited, have the width equal to $60 \mathrm{~nm}$. Their height was about $10 \mathrm{~nm}$ whereas the length reaches several $\mu \mathrm{m}$.

Although the details of the phenomenon that leads to the formation of uniformly distributed parallel wires are not known, we can invoke several mechanisms that should play a leading role. First, a large misfit between $\mathrm{Si}(111)$ and $\mathrm{Pb}(111)$ lattices produces stress that can be relaxed more effectively if long islands grow [4]. The presence of one-dimensional structures on $\mathrm{Si}(533)$ running along [011] azimuth introduces additional asymmetry that aligns the wires along one direction. Secondly, a high mobility of $\mathrm{Pb}$ at $\mathrm{RT}$, reported in Ref. [12] causes a huge mass transport to the end faces of the wires and prohibits the formation of additional nuclei in the course of further $\mathrm{Pb}$ deposition.

\section{Summary}

In summary, using RHEED we have shown that a perfectly ordered $\operatorname{Si}(533)$ surface is formed at Au coverage corresponding to the formation of single Au chains on each $\mathrm{Si}(111)$ narrow terrace. $\mathrm{Pb}$ deposited at $\mathrm{RT}$ on these substrates grew as mesoscopic wires. Using LEEM and STM we have shown also that these wires are about $60 \mathrm{~nm}$ wide and several $\mu \mathrm{m}$ long. The number of wires is determined during a sudden nucleation process after deposition of about $1 \mathrm{ML}$ of $\mathrm{Pb}$. The density of wires is strongly related to the perfection of the $\mathrm{Si}(533)$ substrate. All wires are aligned parallel to the [011] azimuth that is along the step edges. At room temperature the wires have a wedge-like shape. The surrounding flat $\operatorname{Si}(533)$ surface is covered with a $1 \mathrm{ML}$ thick $\mathrm{Pb}$ wetting layer. The elongation of wires is due to the energetically favorable shape that minimise the strain energy caused by lattice misfit. We suggest that the observed strong growth anisotropy is attributed to the step edge barriers and the high and anisotropic $\mathrm{Pb}$ mobility. 


\section{Acknowledgments}

A part of this work was supported by the grant No. 2 P03B 09713 of the Committee for Scientific Research. We are grateful to E. Bauer for his help during LEEM measurements and R. Zdyb for providing Si(533) samples.

\section{References}

[1] H.H. Weitering, D.R. Heslinga, T. Hibma, Phys. Rev. B 45, 5991 (1992).

[2] M. Jałochowski, M. Hoffmann, E. Bauer, Phys. Rev. B 51, 7231 (1995).

[3] M. Jałochowski, E. Baver, H. Knoppe, G. Lilienkamp, Phys. Rev. B 45, 13607 (1992).

[4] J. Tersoff, R.M. Tromp, Phys. Rev. Lett. 70, 2782 (1993).

[5] B.S. Swartzentruber, Y.-W. Mo, M.B. Webb, M.G. Legally, J. Vac. Sci. Technol. A 7, 2901 (1989).

[6] R.J. Phaneuf, N.C. Bartelt, E.D. Williams, W. Swiech, E. Bauer, Phys. Rev. Lett. 67, 2986 (1991).

[7] H. Hibino, T. Ogino, Phys. Rev. Lett. 72, 657 (1994).

[8] R.J. Phaneuf, N.C. Bartelt, E.D. Williams, W. Swiech, E. Bauer, Phys. Rev. Lett. 71, 2284 (1993).

[9] M. Jałochowski, M. Stróżak, R. Zdyb, Surf. Sci. 375, 203 (1997).

[10] P. Adamec, E. Bauer, B. Lencova, Rev. Sci. Instrum. 69, 3583 (1998).

[11] D.J. Chadi, Phys. Rev. B 29, 785 (1984).

[12] J.M. Gómez-Rodriguez, J.J. Sáenz, A.M. Baró, J.-Y. Veuillen, R.C. Cinti, Phys. Rev. Lett. 76, 799 (1996). 